\title{
"... It's Really Ultimately Very Cruel ...": Contrasting English Intensifier Collocations Across EFL Writing and Academic Spoken Discourse
}

\author{
("It's Really Ultimately Very Cruel": Contrastando Colocações de \\ Advérbios de Intensidade em Inglês Entre a Escrita de Aprendizes de \\ EFL e o Discurso Acadêmico Oral de Falantes Nativos)
}

\author{
Leonardo Juliano RECSKI, MA* \\ (Universidade Federal de Santa Catarina)
}

\begin{abstract}
This paper investigates and contrasts recurrent intensifier collocations across a corpus of EFL writing - The International Corpus of Learner English - ICLE (Granger, 1993) and The Michigan Corpus of Academic Spoken English - MICASE (Simpson et al., 2002). It seeks to show that such recurrent collocations are an important part of writers and speakers' linguistic repertoire and that they may provide a window onto their lexicon. On general grounds, the results indicate that there is a great predominance of boosters over maximizers and that a limited number of maximizers and boosters are used in recurrent combinations. The analysis further revealed that maximizers tend to intensify non-gradable words while boosters tend to intensify gradable ones and that EFL writers' overuse of intensifiers appears to be associated with colloquial style and an exaggerated tone that is often considered to be inappropriate in formal academic texts.
\end{abstract}

KEY-WORDs: Intensifiers; Collocation; Maximizer; Booster; EFL Writing; Academic Spoken Discourse.

RESUMo: Este artigo investiga e contrasta colocações recorrentes de advérbios de intensidade entre um corpus composto por textos produzidos em inglês como L2 - o Corpus Internacional de Inglês de Aprendizes - ICLE (Granger, 1993) e o corpus de transcrições de fala de inglês acadêmico da Universidade de Michigan - MICASE (Simpson et al., 2002). O artigo busca demonstrar que a recorrência de tais colocações constitui uma parte importante do repertório lingüístico de falantes e escritores e que,

\footnotetext{
* Acknowledgements: I would like to thank Anna-Brita Stenström and John Swales for making available hard to get articles. I would also like to thank my adviser Dr. Viviane Heberle and two anonymous referees for their pertinent comments on an earlier draft of this paper. Any inconsistencies or problems that still remain are entirely my own.
}

D.E.L.T.A., 20:2, 2004 (211-234) 
assim, pode fornecer uma amostra do léxico dessas populaçoes. De forma geral, os resultados indicam que há uma grande predominância de amplificadores sobre maximizadores e que um número reduzido de maximizadores e amplificadores são utilizados em combinações recorrentes. Além disso, a análise revelou que maximizadores tendem a intensificar palavras não escalares enquanto amplificadores tendem a intensificar palavras escalares e que o uso excessivo de advérbios de intensidade por parte dos aprendizes de L2 parece estar associado a um estilo coloquial e um tom exagerado que são freqüentemente considerados inapropriados em textos acadêmicos formais.

PalavRas-CHaVe: Advérbios de Intensidade, Colocação, Maximizadores, Amplificadores, Escrita Acadêmica em L2, Discurso Acadêmico Oral.

\section{Introduction}

During the past few decades, large corpora of modern English (and other languages) have been made available in computer-readable form. They represent many varieties of English and vary greatly in size (for a survey of such corpora, see Kennedy, 1998). The existence of these corpora enables anyone interested in collocations to investigate such aspects of their occurrence as their frequency, their distribution across genres and their range and typology. It is important here that the character of each corpus is not lost sight of. Collocations occurring in a spoken corpus can be assumed to differ from those in a written one, and those in a non-native (NNS) corpus might differ from those in a native speaker (NS) one, etc. One should also note, using Sinclair's (1991: 109) parlance, that the lexical component of language is "open-ended", that is, corpora inevitably supply only a sample of the words and phrases that are available for language users. The degree to which the phrases in a corpus are representative of those current in the language variety from which they are derived naturally increases with the size of the corpus. However, it is fortunate, then, that smaller corpora, like the MICASE or even ICLE, although they are on the small side for a study of lexis (Manning \& Schütze 2000), are nonetheless large enough to contain a considerable part of the English phrases in current use.

A substantial part of our lexicon consists of words ${ }^{1}$ that customarily collocate with one another (e.g. good morning, of course, very much, etc). If as

\footnotetext{
1 The problems involved in defining 'word' are notorious, and I shall not advance them any further here. For the sake of simplicity, in the present paper a 'word' is seen as any one of the manifestations a lemma may have.
} 
speakers of the language we thus very largely make use of chunks of prefabricated language that allow us to move with dispatch through different discursive settings, and if as listeners we expect other speakers to behave in the same way, this presupposes that anybody who happens to maneuver this mechanism of language will create some sort of a surprise effect. This effect might be undesirable, as when non-native speakers (NNS) put together perfectly grammatical but totally non-native sentences (e.g. to take a decision), or it may be used for specific rhetorical or stylistic purposes (e.g. in poetry, advertising, etc).

It was argued above that collocations or 'language chunks' are an important part of our linguistic repertoire. Therefore it may not be unreasonable to hope that an inventory of such phrases drawn from two modern English corpora and established in a principled fashion may provide a window on our lexicon. On the other hand, it would be extravagant to claim that the inventory would be an accurate representation of (part of) the lexicon in any meaningful sense. This is partly because some of the items they contain are better established than others - there is a continuum from accidental combinations ${ }^{2}$ to universally recognized set phrases (e.g. very good) - and partly because the lexicon will vary from one speaker/ writer to another. The inventory may nevertheless provide a rough sketch of the constitution of the lexicon in the general sense. It may therefore give an indication of the vital role that set phrases or 'collocations' have to play in everyday communication (Sinclair 1991; Biber 1993; Benson et al. 1993) and in EFL teaching and learning (Pawley and Syder 1983; Nattinger \& De Carrico 1992; Aston 1995; Bahns 1993).

\section{The Corpora: MICASE and ICLE}

The reference corpora I will use in this paper consist of a subcorpus of the MICASE, and seven national subcorpora of the ICLE, namely, Finnish, Dutch, French, Spanish, Brazilian, Czech and Polish.

\footnotetext{
2 For example, the title of this paper stemmed from the uniqueness of the intensifier collocation produced by this male American speaker at a Christianity and Modern Family Colloquium (Department of Arts and Humanities) held at the University of Michigan and recorded on February 5, 2001:

... in other words if if women do not prepare themselves, to to be able to be self-supporting and if they commit themselves to the idea that they're gonna be supported for the rest of their lives they're committing themselves to a delusion. So it's really ultimately very cruel yeah?
} 
In the MICASE (Simpson et al. 2002) there are 152 speech events produced totaling 1,688,202 words, all recorded and transcribed at the University of Michigan since 1997. The speech events include PhD Defenses, Colloquiums, Lectures, Advising Sections, etc, across four major academic divisions - Arts \& Humanities, Biological \& Health Sciences, Physical Sciences \& Engineering and Social Sciences \& Education. Table 1 displays the subcorpus of 80 speech events totaling 833,228 words that will be under scrutiny in the present rendering.

The ICLE project (Granger 1993) is a multinational project aiming at identifying the distinctive and shared features of a wide variety of interlanguages. In the project, each national subcorpus contributes with about 200,000 words (about 400 argumentative essays). The subjects who have contributed data to the ICLE share the following attributes. They are young adults (around 20 years old), who are studying English in a non-English speaking environment, i.e. they are EFL, not ESL learners. Their level of proficiency is 'advanced', a notion which is defined on the following grounds: they are university undergraduate in English Language and Literature in their third or fourth year. Although the essays produced cover a variety of topics the content is similar in so far as the topics are mostly non-technical and argumentative. The breakdown for each national subcorpus used in the present study is the following: Czech $-221,583$ words, Spanish $-177,876$ words, Dutch - 130,208 words, French - 134,236 words, Finnish 129,145 words, Brazilian $-33,794$ words and Polish $-33,911$ words. The whole corpus, thus, amounts to 860,753 running words.

\begin{tabular}{|c|c|c|c|c|c|c|c|c|}
\hline \multirow[b]{2}{*}{ Speech Event Type } & \multicolumn{2}{|c|}{ HuM/ARTS } & \multicolumn{2}{|c|}{ Social SCI } & \multicolumn{2}{|c|}{ BIO/ HEALTH SCI } & \multicolumn{2}{|c|}{ Phys sci/ engin } \\
\hline & $\mathrm{s}$ & W & $\mathrm{s}$ & W & S & W & S & W \\
\hline Colloquium & 3 & 39,753 & 2 & 16,837 & 2 & 27,217 & 2 & 22,013 \\
\hline Lecture & 8 & 77,900 & 8 & 83,564 & 8 & 74,172 & 6 & 36,924 \\
\hline Discussion Section & 1 & 8,740 & 4 & 41,390 & 2 & 15,855 & 2 & 13,384 \\
\hline Meetings & & & & & 2 & 19,515 & 2 & 26,485 \\
\hline Advising Sections & 1 & 8,537 & 2 & 15,494 & & & & \\
\hline Defenses & 1 & 15,523 & 1 & 12,236 & 1 & 9,652 & 1 & 21,273 \\
\hline Interview & & & & & 1 & 5,363 & & \\
\hline Museum tour & 1 & 9,032 & & & & & & \\
\hline Office Hours & 2 & 21,786 & 2 & 46,094 & 1 & 8,778 & 3 & 53,115 \\
\hline $\mathrm{Lab}$ & & & 1 & 14,586 & 4 & 43,051 & 3 & 24,853 \\
\hline Tutorials & 1 & 3,725 & & & & & 2 & 16,451 \\
\hline Total & 18 & 184,986 & 20 & 230,201 & 21 & 203,603 & 21 & 214,498 \\
\hline
\end{tabular}

$\mathrm{S}=$ Speech Events, $\mathrm{W}=$ Words

Table 1. Breakdown of speech events and word counts, Subcorpus 1: 80 speech events across four academic divisions 


\section{Amplifiers}

Since it would be too 'forward-looking' to try to account for every possible collocation in the corpora under analysis, the combinations selected for scrutiny were those containing 'amplifiers', i.e. adverbs which are used to express a high degree of intensity, such as completely, absolutely, very, extremely, totally, too, so, etc.

According to Quirk et al. (1985: 589) intensifiers “[do] not refer only to means whereby an increase in intensification is expressed" (original emphasis), rather they "indicate a point on an abstractly conceived intensity scale; and the point indicated may be relatively low or relatively high". The relatively low point on this abstract scale that Quirk et al (1985) describe refers to 'downtoners', one of the major subtypes of intensifiers, whereas the high end of the scale refers to 'amplifiers', which may be subdivided into 'maximizers' and 'boosters' (see Figure 1).

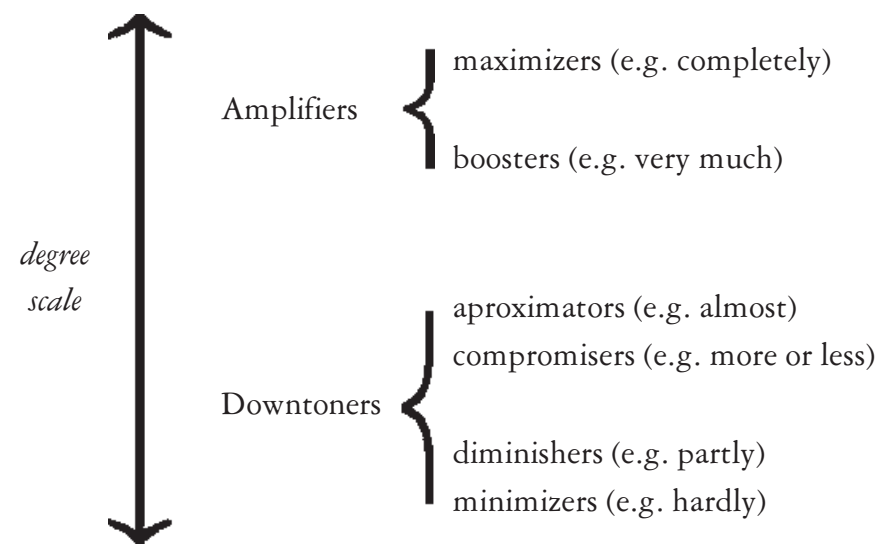

Figure 1. Subtypes of intensifiers (adapted from Quirk et al. 1985: 590)

As can be seen in Figure 1 there are two major types of amplifiers: (i) maximizers (e.g. totally, absolutely, utterly, completely, entirely, etc), which occupy the upper extreme of the degree scale, and (ii) boosters (e.g. extremely, purely, highly, very, so, etc), which convey a high degree but without reaching the extreme end of the scale.

The semantic distinction between maximizers and boosters is that maximizers usually modify 'non-gradable' words (e.g. atomic, electric, painted) or items that already convey an idea of 'extreme' (e.g. repugnant, gigantic, 
astonishing, terrified). Contrarily, boosters, commonly modify 'gradable' words (e.g. nice, ugly, intelligent) (Altenberg 1991).

Amplifiers may be used in various syntactic constructions (Quirk et al. 1985) as the following examples extracted from the corpora attest:

a) as adverbial subjuncts intensifying a predicate:

(1) An army that entively consists of professional soldiers is always motivated because ... [ICLE]

(2) That's why I totally agree that "money is the root of all evil". [ICLE]

(3) ....and we can figure a little flight control to, fully automate the airplane... [MICASE]

b) inside a clause element, mainly as a premodifier of adjectives (4), adverbs (5), determiners

(6), pronouns (7) and prepositional phrases (8):

(4) ...so we have a very complex cascade of events taking place... [MICASE]

(5) ...we know perfectly well, to what extent a rad-an electron can... [MICASE]

(6) There is therefore absolutely no use in obliging young men to... [ICLE]

(7) And uh, I see absolutely nothing wrong with the fact that ... [MICASE]

(8) ....and she was brought up quite apart from her family values and ... [ICLE]

Quirk et al. (1985: 595) bring to our attention that in the majority of cases amplifiers occur before the element they intensify, but as subjuncts they may also occur after the intensified word or at the end of the clause. Therefore, since amplifiers occurring at the end of the clause are often separated from the verb by an object or complement, they are more unlikely to form recurrent combinations than premodified amplifiers, for instance:

(9) I haven't done anything with this at all, Wes did this completely. [MICASE]

(10) ...that's what today's lecture is gonna be about entirely, and ... [MICASE]

In addition, Quirk et al. (1985: 590) point out that maximizers and boosters also differ in an important way. Whereas maximizers form a relatively restricted set, boosters "form open classes, and new expressions are frequently created to replace older ones". What this means is that while it is reasonably easier to compile an inventory of maximizers, this is not the case for boosters.

Another important characteristic of amplifiers is that their collocations are likely to be limited in different ways. For instance, in the corpora under analysis the maximizer utterly mainly collocates with words having negative or unfavorable connotations, for example: 
(11) ...Marx believed that as this worker exploitation became utterly unbearable, that the workers would unite, workers of the world united, and they would stage a revolution ... [MICASE]

(12) ...the medical profession was consider to be utterly unsuitable for women at that time. [ICLE]

Thus, amplifiers form an interesting category to study from a collocational point of view because they are subject to a number of lexical, semantic and syntactic restrictions affecting their use in various ways. More importantly though, amplification "expresses an 'interpersonal' message in what might otherwise be taken to be a purely 'ideational' statement (Partington 1999: 24, cited in Swales \& Burke 2003) and thus have a very important rhetorical role in both spoken and written language.

\section{Research questions}

The amplifiers in the two corpora were analyzed with the purpose of answering the following research questions:

1. What are the types and frequencies of amplifiers used in recurrent combinations in the MICASE and the ICLE corpora? Are these recurrent combinations similar across the two corpora both in range and frequency or are there significant differences because of their different modes, i.e., NS spoken vs. NNS written?

2. What is the range of items collocating with each amplifier across MICASE and ICLE? Are NNS more restricted in relation to their collocational choices?

3. Do the amplifier collocations employed by NNS seem to create an impression of 'wordiness' if compared to those of NS?

The maximizers and boosters included in the present rendering were restricted to adverbs (and few adjectives with adverb function), mainly drawn from the lists in Quirk et al. (1985: 445ff, 490ff), Altenberg (1991: 130140) and Bolinger (1972: 306-308). The following items were examined:

a) 11 maximizers: e.g. absolutely, altogether, completely, entirely, fully, outright, quite, thoroughly, totally, utterly and wholly;

b) 103 boosters, e.g. absurdly, amazingly, awfully, bloody, deeply, definitively, dreadfully, enormously, exceedingly, extremely, greatly, beavily, 
bighly, immensely, incredibly, infinitely, particularly, remarkably, really, so, strongly, terribly, too, tremendously, very, etc.

\section{Collocational recurrence of maximizers and boosters}

The recurrent collocations of maximizers and boosters in the corpora are displayed in Table 2. Table 2 gives the number of combination types each amplifier occurs in, that is to say, the number of different words it occurs with, and the total number of examples (combination tokens) realized by each amplifier ${ }^{3}$.

As can be seen in Table 2, of the 103 boosters examined, only 17 occur in recurrent collocations, while out of the 11 maximizers examined 9 are found in recurrent collocations. This, in turn, reveals the narrow range of items represented in recurrent combinations.

There are, for example, no recurrent collocations of such relatively ordinary boosters as considerably, enormously, greatly, immensely, infinitely and tremendously. Therefore, the first conclusion to be drawn from the two corpora is that both NS and NNS make very limited recurrent use of the practically open-ended repertoire of boosters available to them.

Another salient difference revealed in Table 2 is the primacy of a few frequent items. Among maximizers, 5 of the 8 items (quite, completely, totally, absolutely, perfectly) account for $94 \%$ of the examples in the ICLE corpus and $91 \%$ in the MICASE corpus, and one alone, quite, accounts for $44 \%$ of all maximizers in the ICLE corpus and for $43 \%$ in the MICASE corpus. It is also interesting to note that NNS produced twice more types of combinations than did their NS counterparts, a fact which strikes us as rather surprising, taking into account the fact that the size of the lexicon of NNS is presumably more limited than that of NS. One possible explanation for this NNS abundance of collocation types may reside in the fact that they may not have gained knowledge of an array of different intensifier chunks, thus recurring to a larger number of combinatory possibilities.

\footnotetext{
3 For example, if a text is 1.000 words long it is said to have 1.000 tokens. However, many of these words will be repeated and there may be only 400 different words in the text. Types therefore are the different words. By combination types I mean the number of different words that collocate
} 


\begin{tabular}{|c|c|c|c|c|}
\hline \multirow[b]{3}{*}{ Amplifier } & \multicolumn{2}{|c|}{ ICLE } & \multicolumn{2}{|c|}{ MICASE } \\
\hline & \multicolumn{4}{|c|}{ Number of collocates } \\
\hline & Types & Tokens & Types & Tokens \\
\hline \multicolumn{5}{|l|}{ Maximizers } \\
\hline quite & 44 & 175 & 17 & 75 \\
\hline completely & 23 & 87 & 7 & 35 \\
\hline totally & 16 & 65 & 6 & 17 \\
\hline absolutely & 9 & 24 & 6 & 17 \\
\hline perfectly & 5 & 19 & 5 & 16 \\
\hline entirely & 6 & 13 & 2 & 8 \\
\hline fully & 3 & 8 & 3 & 7 \\
\hline utterly & 1 & 2 & & \\
\hline Total & 101 & 401 & 46 & 174 \\
\hline \multicolumn{5}{|l|}{ Boosters } \\
\hline very & 214 & 1860 & 172 & 1391 \\
\hline really & 24 & 93 & 62 & 404 \\
\hline so & 90 & 616 & 51 & 341 \\
\hline too & 62 & 465 & 28 & 203 \\
\hline extremely & 11 & 36 & 6 & 19 \\
\hline bighly & 8 & 30 & 5 & 14 \\
\hline deeply & 3 & 13 & 2 & 5 \\
\hline particularly & 2 & 4 & 3 & 6 \\
\hline purely & 2 & 4 & & \\
\hline terribly & 1 & 2 & 1 & 2 \\
\hline badly & 1 & 2 & & \\
\hline thoroughly & 1 & 2 & & \\
\hline severely & 1 & 2 & & \\
\hline real & & & 7 & 24 \\
\hline incredibly & & & 3 & 6 \\
\hline heavily & & & 2 & 5 \\
\hline remarkably & & & 1 & 2 \\
\hline Total & 420 & 3129 & 343 & 2420 \\
\hline
\end{tabular}

Table 2. Amplifiers and boosters in recurrent collocations

Among the boosters the situation is similar: in the ICLE corpus 5 of the 13 items account for $98 \%$ of the examples; three of these (very, so, and too) account for $94 \%$, and one alone, very, for $60 \%$ of the examples. An

with each amplifier, whereas by combination tokens I mean the sum of all combination types taken together. For example, the maximizer fully was found in recurrent combinations with the words developed, understand and satisfy, thus it has three combination types. But how many times does it occur with each one of these words? It occurs three times with developed, three times with understand, and twice with satisfy; thus it has eight combination tokens (see Table 2). 
almost identical picture is revealed in the MICASE corpus where 5 of the 13 items account for $98 \%$ of the examples, four of these (very, really, so, and too account for $97 \%$, and very alone accounts for $57 \%$ of the examples. Once again it may be observed that the frequency and range (types) of recurrent combinations produced by the EFL learners outnumber that of NS.

It seems reasonable to suggest that this difference between the two corpora can be ascribed firstly to a difference in mode, i.e., written vs. spoken. Even though native speakers have an automatic command of substantial portions of speech, it is not easy, even for the fluent speaker, to plan many thoughts units ahead, and so s/he relies on those intensifying words and types which are more readily accessible in their lexicon (e.g. really nice, very good, etc). The EFL learners, on the other hand, are producing written work which will probably be accessed by their teachers. They have, therefore, more time to plan their lexical choices so as to achieve the hyperbolic interpersonal effect they want, they may go to dictionaries, ask other colleagues, etc. In sum, there is ample time for reasoning and pondering upon which choices best describe what exactly they want to convey.

Another possible reason for the differences in the two corpora seems to stem from their tenors. Orality and involvement appear to permeate EFL writing and the learners seem to (un)consciously use hyperbolic devices, and many times wrong stylistic choices, when trying to achieve the desired interpersonal effect. Lorenz (1998), in his comparison between the use of intensifiers by Dutch students and native speakers, points out that:

The learners not only use more intensification, they also use it in places where it is semantically incompatible, communicatively unnecessary or syntactically undesirable. [...] What seems to be at fault, then, is the whole writing attitude, EFL student writing appears to be more geared towards creating an impression than towards arguing a case (Lorenz 1998: 64)

Finally, another noticeable feature across the two corpora is the great predominance of a few frequent boosters among the amplifiers. As shown in Table 2, this predominance applies to both combination types and combination tokens across the two corpora. What this means is that boosters seem to be more 'multipurpose' (they combine with a wider range of words) and more 'abundant' (used in more examples) than the maximizers.

The analysis so far has revealed that (i) there is a limited range of amplifiers in recurrent collocations; (ii) there is a strong concentration of a 
few frequent items; (iii) there is a significant predominance of boosters over maximizers; and (iv) there is an overuse of amplifier collocations in EFL writing possibly resulting from both the tenor and mode represented in argumentative writing.

As we shall see below, the high frequency amplifiers very, really, so and too tend to serve as 'multipurpose' items that can replace almost all other alternatives in most functions. Nonetheless, the limited range of amplifiers represented in the material is also due to the fact that they are exclusively drawn from recurrent collocations. Since amplifiers also commonly occur in non-recurrent collocations, their total number and frequency in the corpora is generally much greater than Table 2 indicates. In other words, the table gives a considerably understated picture of actual usage. This distortion should be borne in mind in the following discussions.

Last but not least, the collocational range (types) and number of collocation types lends support to the interpretation that the more frequent the amplifier is, the more 'multifunctional' it tends to be, and vice versa. In order to get a more detailed picture of the collocational proneness of the amplifiers the collocations will be examined more thoroughly.

\section{The most frequent amplifier collocations across ICLE and MICASE}

Table 3 shows the 30 most frequent amplifier collocations in each corpus. Even though the table only shows a small portion of the total number of recurrent collocation types (6\% in the ICLE corpus and $8 \%$ in the MICASE corpus), it covers $38 \%$ of the tokens in the ICLE corpus and $47 \%$ of the tokens in MICASE. It therefore stresses one of the points raised above very plainly: the strong preponderance of a few very frequent amplifiers - very, really, so, and too among the boosters, and only completely among the maximizers.

Table 3 also shows that the boosters commonly modify gradable items (much, good, well), while the maximizer completely was typically used to modify a non-gradable item (different). Most of the items these amplifiers modify are very common words denoting quality, mainly with positive connotations (easy, good, well, important, interesting, useful), but some also have a negative input (difficult, dangerous, expensive, hard). 
D.E.L.T.A., 20:2

\begin{tabular}{|c|c|c|c|c|c|}
\hline \multicolumn{3}{|c|}{ ICLE } & \multicolumn{3}{|c|}{ MICASE } \\
\hline Combination & Frequency & Type & Combination & Frequency & Type \\
\hline very important & 164 & booster & very very & 109 & booster \\
\hline so much & 143 & booster & very much & 100 & booster \\
\hline too much & 124 & booster & so much & 90 & booster \\
\hline very often & 99 & booster & very good & 87 & booster \\
\hline very much & 95 & booster & too much & 66 & booster \\
\hline so many & 88 & booster & very interesting & 57 & booster \\
\hline very difficult & 85 & booster & very important & 54 & booster \\
\hline very little & 65 & booster & very well & 50 & booster \\
\hline very good & 55 & booster & very different & 48 & booster \\
\hline very different & 50 & booster & so many & 47 & booster \\
\hline too many & 36 & booster & really good & 46 & booster \\
\hline very hard & 34 & booster & very small & 35 & booster \\
\hline completely different & 30 & maximizer & really important & 34 & booster \\
\hline too far & 30 & booster & very high & 29 & booster \\
\hline very few & 29 & booster & really really & 28 & booster \\
\hline very easy & 28 & booster & very similar & 27 & booster \\
\hline too late & 27 & booster & very simple & 26 & booster \\
\hline very common & 25 & booster & really interesting & 25 & booster \\
\hline very useful & 24 & booster & really different & 25 & booster \\
\hline very strong & 24 & booster & very long & 23 & booster \\
\hline very dangerous & 24 & booster & very hard & 23 & booster \\
\hline so important & 24 & booster & very little & 22 & booster \\
\hline so easy & 22 & booster & too many & 22 & booster \\
\hline very expensive & 21 & booster & completely different & 20 & maximizer \\
\hline very interesting & 20 & booster & very quickly & 18 & booster \\
\hline very quickly & 19 & booster & really hard & 18 & booster \\
\hline very bad & 18 & booster & very close & 18 & booster \\
\hline very simple & 18 & booster & very few & 17 & booster \\
\hline very serious & 17 & booster & very difficult & 17 & booster \\
\hline very high & 17 & booster & so good & 16 & booster \\
\hline
\end{tabular}

Table 3. The 30 most frequent amplifier collocations across ICLE and MICASE 
Interestingly, in the MICASE the most frequent recurrent collocation was very very. This, speculatively, allows us to infer that academic spoken discourse has more affinity to casual speech than to formal prose.

Note that seventeen out of the top thirty recurrent collocations are the same; note also that among the top ten, i.e., the most prominent ones, seven are identical. This lexical accordance, of course, becomes fuzzier in the lower frequencies, but even for those it can be shown that the items still share collocational similarities. By highlighting the same kinds of adjectives, NNS and NS, thus, seem to be doing the same thing, at least semantically.

By and large, both populations tend to intensify adjectives that display what they consider to be important, different, interesting, in sum, pertinent and relevant. In addition, 'nuclear' adjectives such as long, little, hard, good, bad (Carter 1987) are the ones which are most commonly intensified.

Functionally speaking, the major reasons for using such recurrent collocational patterns appear to be to attract the reader/listener's attention and enhance the meaning of 'colorless' adjectives. Nonetheless, as both NNS and NS relate to each other on this preference, there cannot be a purely functional explanation for the difference in terms of combination tokens shown in Table 3.

The picture revealed in Table 3 is nevertheless a very crude one: it tells us little about the collocational properties of the different maximizers and boosters. By examining the less frequent combinations in more detail we are able to get a better understanding of these amplifiers. I shall discuss maximizer and booster collocations separately in the following sections. For each type, I will provide a full list of recurrent collocations across both corpora (except those of very, so, really and too, which are too frequent and varied to be specified in full).

\section{Maximizer collocations}

The following maximizer collocations were found in the ICLE and MICASE corpora (see Figure 2, numbers indicate the number of times the combination occurred): 


\begin{tabular}{|c|c|c|}
\hline Maximizer & ICLE & MICASE \\
\hline Quite & 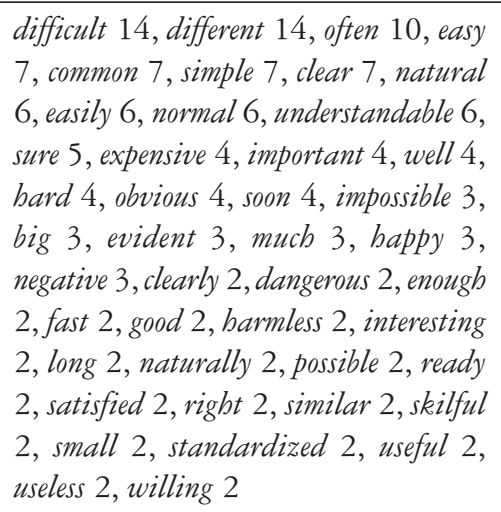 & $\begin{array}{l}\text { white } 12 \text {, different } 11 \text {, sure } 6 \text {, common } \\
6 \text {, work } 5 \text {, some } 5 \text {, right } 5 \text {, know } 4 \text {, } \\
\text { often } 3 \text {, interesting } 3 \text {, well } 3 \text {, awhile } \\
2 \text {, go } 2 \text {, quickly } 2 \text {, rarely } 2 \text {, simple } 2 \text {, } \\
\text { understand } 2\end{array}$ \\
\hline Completely & $\begin{array}{l}\text { different } 31 \text {, true } 7 \text {, dependent } 4 \text {, changed } \\
4 \text {, negative } 3 \text {, new } 3 \text {, lost } 3 \text {, agree } 2, \text { bad } \\
2 \text {, dedicated } 2 \text {, defenseless } 2 \text {, depend } 2 \text {, } \\
\text { equal } 2 \text {, forget } 2 \text {, free } 2 \text {, happy } 2 \text {, honest } \\
2 \text {, isolated } 2 \text {, subordinated } 2 \text {, unreal } 2 \text {, } \\
\text { upside down } 2 \text {, useless } 2 \text {, wrong } 2\end{array}$ & $\begin{array}{l}\text { different } 20 \text {, wrong } 3 \text {, fill } 3 \text {, separate } \\
3 \text {, understand } 2 \text {, baked } 2 \text {, honest } 2\end{array}$ \\
\hline Totally & $\begin{array}{l}\text { different } 20 \text {, agree } 8 \text {, dependent } 6 \text {, new } \\
4 \text {, devoted } 3 \text {, obvious } 3 \text {, true } 3 \text {, rejected } \\
2 \text {, against } 2 \text {, aware } 2 \text {, bad } 2 \text {, good } 2 \text {, } \\
\text { isolated } 2 \text {, lost } 2 \text {, sure } 2 \text {, unbelievable } 2\end{array}$ & $\begin{array}{l}\text { different } 6 \text {, wrong } 3 \text {, differently } 2 \text {, great } \\
2 \text {, slacked off } 2 \text {, understand } 2\end{array}$ \\
\hline Absolutely & $\begin{array}{l}\text { no } 5 \text {, nothing } 4 \text {, necessary } 4 \text {, not } 3 \text {, } \\
\text { independent } 3 \text {, impossible } 2 \text {, perfect } 2 \text {, } \\
\text { right } 2 \text {, sure } 2\end{array}$ & $\begin{array}{l}\text { no } 5 \text {, nothing } 3 \text {, true } 3 \text {, right } 2 \text {, correct } \\
2 \text {, necessary } 2\end{array}$ \\
\hline $\begin{array}{l}\text { Perfectly } \\
\text { Entirely }\end{array}$ & $\begin{array}{l}\text { well } 7 \text {, know } 4 \text {, happy } 3 \text {, fit } 3 \text {, clear } 2 \\
\text { controlled } 3 \text {, new } 2 \text {, up to you } 2 \text {, different } \\
2 \text {, justified } 2 \text {, consists } 2\end{array}$ & $\begin{array}{l}\text { well } 5 \text {, good } 4 \text {, fine } 3 \text {, obvious } 2 \text {, elastic } \\
2 \text { different } 6 \text {, work } 2\end{array}$ \\
\hline $\begin{array}{l}\text { Fully } \\
\text { Utterly }\end{array}$ & $\begin{array}{l}\text { developed 3, understand 3, satisfy } 2 \\
\text { impossible } 2\end{array}$ & automate 3 , exploit 2 , implemented 2 \\
\hline
\end{tabular}

Figure 2. Maximizer collocation across ICLE and MICASE

By and large, quite is the maximizer most frequently employed by both populations and practically the only one used to intensify ly-adverbs (easily 6, naturally 2, clearly 2, quickly 2, rarely, the exception being totally which was used to intensify differently). When quite functions as a subjunct, specially in spoken discourse, it is often used with non-gradable verbs in contexts where the speaker is not very confident as examples (11) to (13) extracted from the corpora attest: 
(11) ... well, I'm, I'm, I'm concerned now I don't quite understand what the point of your ... [MICASE]

(12) ... maybe there's one point where this doesn't quite work ... [MICASE]

(13) ... we believe actually based on work I I can't quite go into now, um, that ... [MICASE]

Completely, the second most common maximizer, is the primary choice with different, true and wrong, and a second alternative with new and agree. It also occurs with adjectives which have a negative import such as wrong, dependent, negative, defenseless and useless.

Absolutely is the only maximizer which intensifies negative items like no, not and nothing. Moreover, absolutely occurs as the only choice with the adjectives necessary, independent, correct, and impossible.

Totally is the primary choice for the verb agree, and the secondary choice for the adjective different being in close competition with completely, quite and entirely. Perfectly tends to collocate with words with a positive import and occurs as the only maximizer with fine. Entirely is the only maximizer which collocates with controlled and justified and it is the secondary choice with new. Fully is the primary choice for the verb understand and appears to have a strong tendency to collocate with other verb types (satisfy, automate, exploit).

As can be noticed, both the number of types and tokens of maximizer collocations employed by NNS outnumber those of NS. It is plausible to argue that in need of a native-like command of the vocabulary, NNS frequently use intensified adjective combinations where NS would simply use a single suitable adjective. Two examples will help clarify this point:

(14) I agree that dominating the others is absolutely ugly. [ICLE-Czech]

(15) ... if you manage to get to the front of this box you will have an absolutely excellent view of the match. [ICLE-Dutch]

By looking at example (14), one does in fact get the idea that this EFL writer graded her/his adjective too weak for her/his argumentative purpose. She/he chose to intensify it with absolutely - an unwise choice, perhaps, given that ugly is a middle-term gradable adjective and does not often collocate with a maximizer. A better choice in (14) would have been horrible instead of absolutely ugly. In example (15), we have the reverse situation - 
excellent is already a superlative adjective and therefore it is not, normally, intensified.

After the aforesaid, one can speculate that this difference in terms of tokens and types of maximizer collocations has to do with a certain insecurity among NNS regarding the effectiveness of their writing. Anxious to make an impression and conscious of their limited linguistic repertoire, NNS writers might feel a greater need to stress the importance of what they have to say.

\section{Booster collocations}

The following booster collocations were found in the ICLE and MICASE corpora (see Figure 3):

\begin{tabular}{|c|c|c|}
\hline Booster & ICLE & MICASE \\
\hline Very & 214 collocation types, 1860 tokens & 172 collocation types, 1381 tokens \\
\hline Really & 24 collocation types, 93 tokens & 62 collocation types, 404 tokens \\
\hline So & 90 collocation types, 606 tokens & 51 collocation types, 341 tokens \\
\hline Too & 62 collocation types, 465 tokens & 28 collocation types, 203 tokens \\
\hline Extremely & $\begin{array}{l}\text { important 9, difficult 6, dangerous } 4 \text {, } \\
\text { useful 3, complex 2, bigh 2, poor 2, }\end{array}$ & $\begin{array}{l}\text { important 6, difficult 3, influential 2, } \\
\text { large 2, short 2, useful 2 }\end{array}$ \\
\hline Highly & powerful 2, small 2, successful 2, violent 2 & soluble 4 diverse 3 carrelated 2 \\
\hline Highly & $\begin{array}{l}\text { developed } 11, \text { qualified } 4, \text { unlikely } 4 \text {, } \\
\text { respected } 3 \text {, charged } 2 \text {, irrationally } 2 \text {, } \\
\text { impossible } 2 \text {, technical } 2\end{array}$ & $\begin{array}{l}\text { soluble } 4 \text {, diverse } 3 \text {, correlated } 2 \text {, } \\
\text { fragmented } 2 \text {, expressed } 2\end{array}$ \\
\hline Deeply & rooted 9 , influenced 2, believe 2 & notched 3, compromised 2 \\
\hline Particularly & difficult 2, important 2 & difficult 2, strong 2 , well 2 \\
\hline Purely & economic 2 , practical 2 & \\
\hline Terribly & sad 2 & $\operatorname{good} 2$ \\
\hline Greatly & improved 2 & \\
\hline Severely & punished 2 & \\
\hline Thoroughly & trained 2 & \\
\hline Badly & needed 2 & \\
\hline Real & & $\begin{array}{l}\text { quick } 7 \text {, good 6, fast 3, big } 2 \text {, } \\
\text { important 2, nice 2, quickly } 2\end{array}$ \\
\hline Incredibly & & bigh 2 , important 2 , recent 2 \\
\hline Heavily & & phosphorylated 3 , weighted 2 \\
\hline Remarkably & & incomplete 2 \\
\hline
\end{tabular}

Figure 3. Booster collocations across ICLE and MICASE

Boosters normally amplify gradable items - words like many, difficult, good, nice, much, beautiful, etc. As has been mentioned earlier, boosters have 
a broader collocational range than do maximizers; in fact, most of them are actually interchangeable. Emotive and stylistic factors seem to be the key factor for choosing which booster to use (e.g. for a stronger hyperbolic effect a speaker/writer will probably choose extremely instead of very).

Very, so, really and too are the boosters par preference of adjectives and adverbs. A distinguishable difference between NNS and NS's use of booster is the number of tokens which are revealed for certain collocations. For example, in the NNS corpus very important is the most frequent booster combination accounting for three times more tokens than the NS counterpart. A reasonable explanation for such difference lies in the fact that important is used by NNS as a key adjective to pinpoint those portions of the text which they want to highlight. The reader, in turn, will treat these expressions as signposts through the text and will expect these stretches of text to contain vital information.

The booster combination very very, the most frequent across MICASE, was commonly employed to intensify gradable adjectives (bad, big, delicate, efficient, funny, good, interesting, kind, simple, small, strong, tiny, etc.) the same being true for the combination really really (beautiful, bright, cool, hard, upset, etc).

Altenberg (1991: 140) draws to our attention that for reasons of euphony, very and so are frequently employed to intensify -ly adverbs (very differently, so precisely). The booster very was frequently employed with past participles often to refer to states or qualities (examples 16 and 17) and with verbs which express personal reactions (examples 18 and 19). For example:

(16) ... now, this is a, very complicated problem to analyze um, you know the ideal ... [MICASE]

(17) The journey takes them up to two hours and they are all very tired and exhausted by the end of the day. [ICLE]

(18) ... and Manet like Courbert is very concerned with real life. [MICASE]

(19) But when Huck and Jim are about to reach a state in which Jim will be a free man Jim gets very excited. [ICLE]

Very only occurred with a few present participles: those which function as adjectives (e.g. very interesting, challenging, soothing, confusing, puzzling), and it was used three and seventeen times respectively to modify the 
numeral first and the superlative best (e.g. very best book, very best moment, very first page, very first studies). Very much occurred only once modifying a comparative (very much longer)

I found that really occurred with a density of 26,1 per 10,000 words in the MICASE and 8,2 per 10,000 words in the ICLE, a considerable difference which marks really a characteristic lexical item of speech. The most common adjectives that immediately followed really are more or less what we might expect: good (46), important (34), interesting (25) hard (18), nice (14) and bad (12) in the MICASE, and important (9), hard (8), necessary (7), happy (7), difficult (5) and good (4) in the ICLE. The vast majority of these are replaceable without too much strain by very. Further, the overall frequencies and types of combinations found for really in MICASE are broadly similar to those for British and American conversation reported in Biber et al., (1999). In this respect, the MICASE data shows a much greater affinity to casual speech as opposed to formal prose.

As for so, the most common collocates found in the ICLE were much (143), many (88), important (24), easy (22) and bad (14), while in the MICASE much (90), many (47), good (16) and different (14) were the most prominent ones.

In very formal writing style, it is possible to use so to intensify an adjective in the structure so + adjective $+a(n)+$ noun. Given its rather literary tone, it was rather surprising to find NNS employing such construction as the examples below demonstrate (no such examples were found in NS spoken discourse):

(20) For example in China expressing an opinion might be so serious a crime that it leads to a death sentence. [ICLE-Finnish]

(21) One does not have to be soprivileged a person as before, to be able to have and express opinions of social injustices. [ICLE-Polish]

Another very common structure employed by both NNS and NS populations regards the expression so + adjective followed by that-clauses. In such structures (a total of 143 across both corpora), the reader/listener is directed to results and/or consequences which derive from the intensification. For instance: 
(22) The presenter makes awful jokes and is so posh that you would not be able to endure him in any other place, but somehow he seems the right man for the show. [ICLE]

(23) ... and in fact, this thing, is so interest-sensitive, that this story works, with, an infinitesimal an indivisible, reduction, in $\mathrm{R}$... [MICASE]

(24) There are, obviously, crimes so abhorrent that they could hardly be performed by a psychologically balanced individual. [ICLE]

The booster too was most frequently employed in affirmative sentences collocating with many and much across both corpora. Too was also often (103 occurrences) used in the structure too + adjective/adverb + infinitive (e.g. too busy to worry about nature, too quickly to understand) and marginally used (17 occurrences), only by NNS, premodified by words like far, much and quite (e.g. most people are far too enthusiastic, it is much too bot here, I find it quite too strong an idea) and by both NNS and NS in a too + adjective + forclause structure (29 occurrences) (e.g. too complex for man to understand, too warm for February, too heavy for the structure).

Extremely, appears as one of the biggest competitors of very, so, really and too. Its hyperbolic tone was frequently used to describe things that extend far beyond the norm or that represent the utmost degree or point. There does not seem to be any particular collocational restriction in relation to what types of items extremely may intensify, and thus, we find it intensifying both positive and negative things (e.g. extremely useful, extremely successful, extremely poor, extremely violent).

Similarly to Altenberg's (1991) findings, in the two corpora used in this study, highly tended to collocate with past participle adjectives denoting a positive feature of something or someone (e.g. highly developed, highly qualified, highly respected) whereas deeply was commonly used to intensify negative words (deeply influenced, deeply rooted, deeply compromised).

The word real only appeared as an adjectival intensifier in the MICASE corpus. It was mainly used to intensify commonly used gradable adjectives such as good, nice, important, fast and quick.

The other boosters are too scarce to display any collocational pattern. Nevertheless, some tendencies do appear to shore up. For example, terribly, badly and severely, rather expectedly, tended to collocate with unfavorable words (e.g. terribly sad, badly needed, severely punished; an exception being terribly good). 


\section{Frequent words intensified by both maximizers and boosters}

In this section I take a look at the concurrence between different maximizers and boosters. Taking into account the fact that the number of intensified words is extremely vast, I will concentrate only on those words which were intensified by at least six different maximizers and/or boosters, i.e. where these different amplifiers are used to intensify the same word.

Table 4 displays fourteen words intensified by at least six amplifiers across both corpora. The figures provided in Table 4 indicate the number of times the collocation occurred in both corpora.

It can be noticed in Table 4 that three boosters - very, so and really are used to amplify almost any lexical item (gradable or not). Likewise, the maximizer quite is also employed in a similar way (except by high and true). This tendency was also reinforced for other, less recurrent, lexical items.

As we have seen, non-gradable items are typically intensified by maximizers across NNS and NS corpora. Words constantly treated in this way are for example sure (15), true (14), new (13), clear (9), wrong (8), the verbs agree (10), understand (9) and work (7), the determiner no (10) and the pronoun nothing (7). Nevertheless, as shown in Table 4, the adjectives different, true and new were also intensified by boosters. It may be argued that this propensity to interpret typically non-gradable words as gradable and vice versa often seems to be emotionally tinged. Thus, depending on the interpersonal impact that the speaker/writer wants to achieve, she/he will play down the force of the intensification. This strategy was consciously employed by both NS and NNS.

The other way around, that is, the conversion of a typical gradable word into a non-gradable one was also frequent in the material analyzed. This, again, is shown in Table 4, where ten gradable adjectives were also intensified by maximizers. Three of these adjectives, good, different and happy, appear as the ones which display more overlap between the choice of a booster or a maximizer, specially different, which was very commonly intensified by quite, completely and perfectly (101 tokens). Once again it appears as though strong interpersonal effects demand strong expressions, and sometimes the expression of extreme degree can only be achieved by a shift from booster to maximizer. This is clearly illustrated by good and happy above, which are both converted into non-gradable adjectives when a maximal degree of intensity is required (perfectly good, completely happy). 


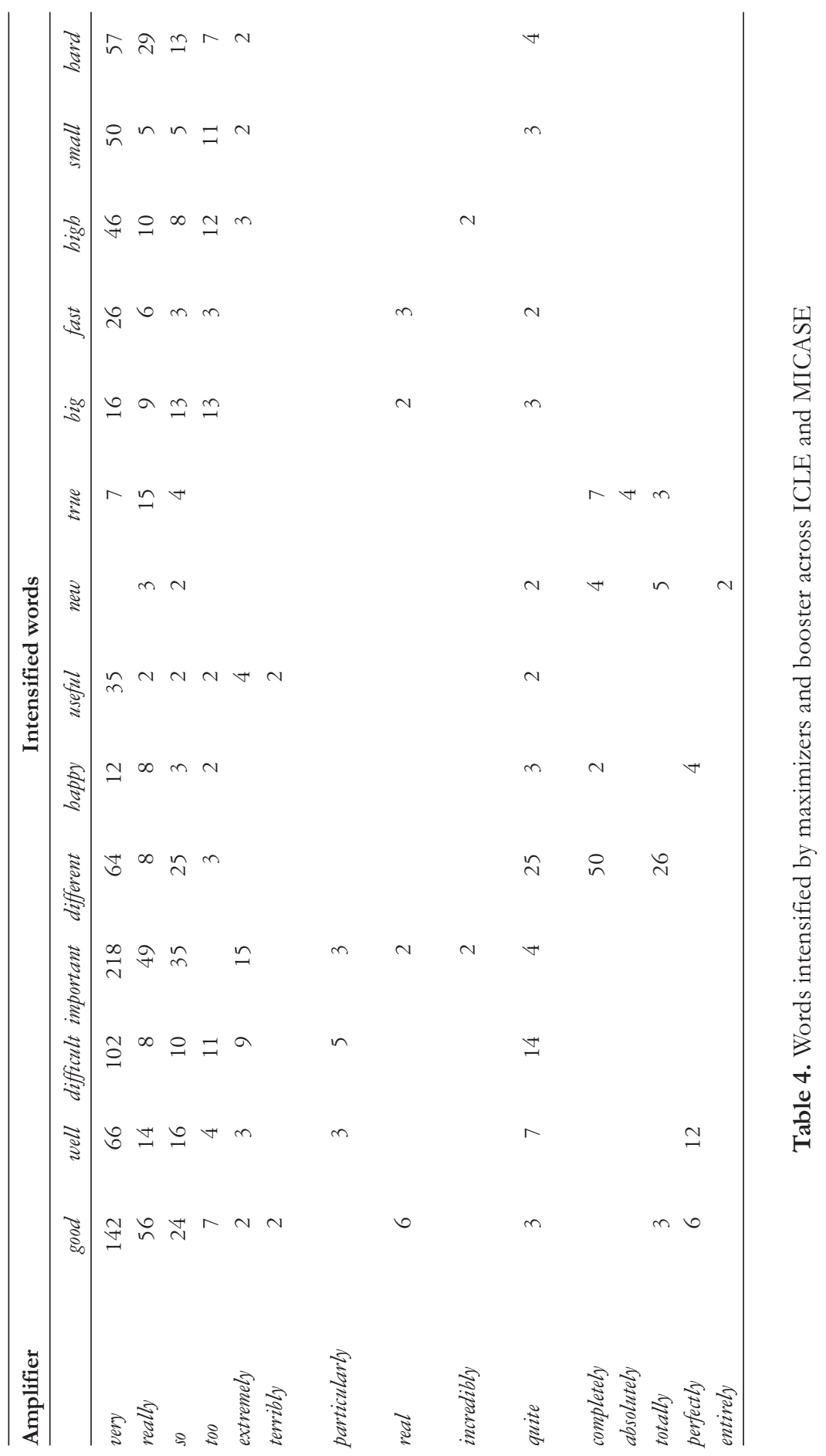




\section{Conclusion}

As it has been claimed in the outset of this paper, it would be extravagant to claim that the inventory of intensifier collocations which emerged from an analysis of both the ICLE and the MICASE corpus would be an accurate representation of the lexicon of NNS and NS in any meaningful sense. Like any corpora, it allows us to observe what happens to be represented in them, and by disregarding non-recurrent collocations it confines our possibilities of observation still further.

Nonetheless, apart form these limitations, the inventory provided in this study may offer an indication of the constitution of the lexicon of both NNS and NS across written and spoken registers. By excluding what is non-recurrent, and emphasizing what is recurrent, this study provides a 'snapshot' of the amplifier collocations that are favored by repeated use in written and spoken discourse in two different populations.

In sum, we can say that the following features of intensifier collocations have emerged from the material examined in the paper:

(i) a limited number of maximizers and boosters are used in recurrent combinations;

(ii) there is a great predominance of boosters over maximizers;

(iii) although there is some degree of overlap between which lexical items maximizers and boosters may intensify, maximizers generally intensify non-gradable items whereas boosters tend to intensify gradable ones (Altenberg 1991);

(iv) boosters display a great collocational freedom, i.e., different boosters are used to intensify the same lexical items;

(v) there is a strong association of some maximizers with certain semantic types of collocates (e.g. completely and absolutely commonly collocates with adjectives that have a negative import, perfectly collocates with items which convey positive qualities, fully tends to collocate with verbs);

(vi) EFL writers' overuse of intensifiers can be tentatively associated with a colloquial style and an exaggerated tone that is often considered to be inappropriate in formal academic texts. This overuse may also be the outcome of the writers' lack of other more appropriate lexical means of developing academic argumentation. The high occurrence of a few boosters 
(particularly very, so and too) identified in NNS compositions additionally points to the colloquial style and limited lexical repertoire of NNS prose. Such overuse of intensifiers is also corroborated in other studies which found that NNS writers frequently rely on a more limited lexical and syntactic range of these devices and employ them with significantly higher frequencies than NS students with a similar level of schooling (Lorenz 1998, 1999; Hinkel 1997; Hyland \& Milton 1997).

Therefore, regardless of its shortcomings, the corpora offer an extremely valuable instrument for studying intensifier collocations. The use of such empirical information in contrast to the possible arbitrariness and unreliability of intuitive judgments is, hence, one contribution which studies of this kind can make to language pedagogy. Obviously, it is not easy to predict what particular quantitative information can be of pedagogical significance. It would seem to be clear that intensifiers, like other lexical items, are learned not as representatives of word classes or as lexemes in isolation, but in association with other words. Thus, collocational studies of this kind can serve to deepen existing descriptions in textbooks, grammars and dictionaries.

E-mail: Irecski@hotmail.com

Recebido em fevereiro de 2003 Aprovado em novembro de 2003

\section{REFERENCES}

Altenberg, Bengt. 1991. Amplifier collocations in spoken English. In: Stig. Johansson \& Anna-Brita. Stenström (Eds.) English Computer Corpora. Berlin: Mouton de Grutyter: 127-148.

Aston, Guy. 1995. Corpora in language pedagogy: Matching theory should we teach EFL students collocations? System, 21(1): 101-114.

Bahns, Jens. 1993. Lexical Collocations: A Contrastive View. English Language Teaching Journal 47(1): 56-63.

Benson, Morton; Evelyn Benson \& Robert Ilson. 1993. The BBI Combinatory Dictionary of English. Amsterdam: John Benjamins.

BIBER, Douglas. 1993. Co-occurrence patterns among collocations: a tool for corpus-based lexical knowledge acquisition. Computational Linguistics 19: 549-556. 
Bolinger, Dwight. 1972. Degree words. The Hague: Mouton.

CARTER, Ronald. 1987. Is there a core vocabulary? Some implications for language teaching. Applied linguistics 8(2): 178-192.

Granger, Sylviane (ed.). 1998. Learner English on Computer. London and New York: Longman.

Granger, Sylviane. 1993. International Corpus of Learner English. In: Papers from the Thirteenth International Conference on Language Research on Computerized Corpora, Nijmengen 1992. Jan Aarts, Picter de Haan and Nellake Ostdijk (eds.). Amsterdam-Atlanta, GA: Rodopi: 57-72. HinkEL, Eli. 1997. Indirectness in L1 and L2 academic writing. Journal of Pragmatics 27: 361-386.

HYLAND, Ken \& John Milton. 1997. Qualifications and certainty in L1 and L2 students' writing. Journal of Second Language Writing 6: 183 -206.

Kennedy, Graeme. 1998. An Introduction to Corpus Linguistics. Harlow: Addison Wesley Longman.

LORENZ, Gunter. 1998. Overstatement in advanced learners' writing: stylistic aspects of adjective intensification. In: Sylviane Granger (Ed.) Learner English on Computer. London and New York: Longman: 53-66. . 1999. Adjective intensification - learners versus native speakers. Amsterdam: Rodopi.

Manning, Christopher \& Schütze, Hinrich. 2000. Foundations of Statistical Natural Language Processing. Cambridge, Massachusetts: The MIT Press.

Nattinger, James R. \& Jeannete S. DeCarrico. 1992. Lexical Phrases and Language Teaching. Oxford University Press: Oxford.

Partington, Alan. 1999. Patterns of meaning. Amsterdam: John Benjamins. Pawley, Andrew \& Syder, Frances. 1983. Two Puzzles for Linguistic Theory. In J.C. Richards and R.W. Schmidt (eds.) Language and Communication. London: Longman: 191-226.

Simpson, Rita; Sarah Briggs; Jeanne Ovens \& John Swales. 2002. The Michigan Corpus of Academic Spoken English. Ann Arbor, MI: The Regents of the University of Michigan.

Sinclair, John. 1991. Corpus, Concordance, Collocation. Oxford, UK: Oxford University Press.

SwALES, John \& BURKE, Amy 2003. "It's really fascinating work": Differences in Evaluative Adjective across Academic Registers. In P. LeISTYNA \& C. F. Meyer (Eds.) Corpus Analysis: Language Structure and Language Use. Amsterdam - New York: Rodopi: 1-18.

Quirk, Randolf; Sydney Greenbaum; Geoffrey Leech, \& Jan Svartvik. 1985. A Comprehensive Grammar of the English Language. London: Longman. 